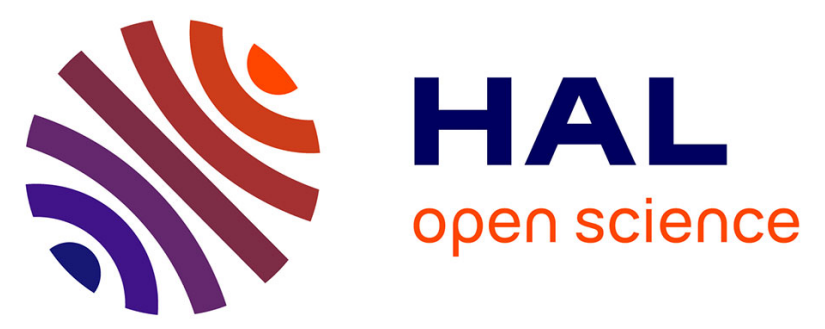

\title{
Abrupt and unexpected stressful life events are followed with increased disease activity in spondyloarthritis: A two years web-based cohort study
}

Guanguan Luo, Pierre Yves Boelle, Clément Turbelin, Félicie Costantino, Solen Kerneis, Roula Said Nahal, Maxime Breban, Thomas Hanslik

\section{To cite this version:}

Guanguan Luo, Pierre Yves Boelle, Clément Turbelin, Félicie Costantino, Solen Kerneis, et al.. Abrupt and unexpected stressful life events are followed with increased disease activity in spondyloarthritis: A two years web-based cohort study. Joint Bone Spine, 2019, 86 (2), pp.203 - 209. 10.1016/j.jbspin.2018.05.009 . hal-03486460

\section{HAL Id: hal-03486460 \\ https://hal.science/hal-03486460}

Submitted on 20 Dec 2021

HAL is a multi-disciplinary open access archive for the deposit and dissemination of scientific research documents, whether they are published or not. The documents may come from teaching and research institutions in France or abroad, or from public or private research centers.
L'archive ouverte pluridisciplinaire HAL, est destinée au dépôt et à la diffusion de documents scientifiques de niveau recherche, publiés ou non, émanant des établissements d'enseignement et de recherche français ou étrangers, des laboratoires publics ou privés.

\section{(ㄷ)(1) $\$$}

Distributed under a Creative Commons Attribution - NonCommerciall 4.0 International 


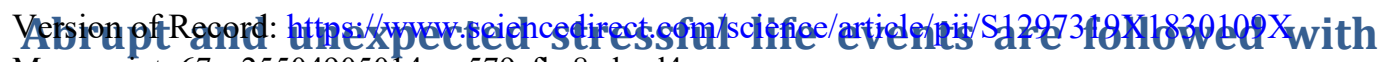
Manuscript 67ea255049050 14ecc579afbe8adecd4 4 increased disease activity in spondyloarthritis: a two years web-

\section{based cohort study}

Guanguan Luo ${ }^{1, *}$, Pierre Yves Boelle ${ }^{1}$, Clément Turbelin ${ }^{1}$, Félicie Costantino ${ }^{2,3}$, Solen Kerneis $^{5,6,7}$, Roula Said Nahal ${ }^{3}$, Maxime Breban ${ }^{2,3, \#}$, Thomas Hanslik ${ }^{1,2, \grave{e}, \#}$

\# The last two authors contributed equally to the work

(1) Sorbonne Universités, UPMC Université Paris 06, INSERM, Institut Pierre Louis d'épidémiologie et de Santé Publique (IPLESP UMRS 1136), 75013, Paris, France

(2) INSERM UMR 1173, UFR Simone Veil, Université de Versailles-Saint-Quentin, 78180 Montigny-le-Bretonneux, France

(3) Service de rhumatologie, hôpital Ambroise Paré, AP-HP, 92100, Boulogne Billancourt, France

(4) AP-HP, Hôpitaux Universitaires Paris Centre-Site Cochin, Equipe Mobile d'Infectiologie, Paris, France ; Université Paris Descartes, Sorbonne Paris cité, 75006 Paris, France

(5) INSERM 1181 Biostatistics, Biomathematics, Pharmacoepidemiology, and Infectious Diseases (B2PHI), 75015 Paris, France;

(6) Institut Pasteur, Versailles Saint-Quentin University, UMR 1181, B2PHI, 78180 Montigny-leBretonneux, France

(7) Service de médecine interne, Hôpital Ambroise Paré, AP-HP, 92100, Boulogne Billancourt, France

*Author's present address: Department of Emergency, Zhongnan hospital of Wuhan University, China

\section{Corresponding author}

Thomas HANSLIK

Service de Médecine Interne, Hôpital Ambroise Paré, 9, avenue Charles de Gaulles, 92100 Boulogne Billancourt, France Tel: +331 490956 51, Fax: +33149095649

e-mail: thomas.hanslik@aphp.fr

(C) 2018 published by Elsevier. This manuscript is made available under the CC BY NC user license https://creativecommons.org/licenses/by-nc/4.0/ 


\section{Abstract:}

Objective: The contribution of environmental factors to spondyloarthritis $(\mathrm{SpA})$ course remains poorly characterized. We previously reported a possible triggering of disease flares by stressful life events and vaccination. The objective of the present study was to specify the types of vaccine and life event that may influence disease activity.

Methods: A prospective cohort of adult SpA was followed for two years. Patients logged on to a secured website every month to complete a standardized auto-questionnaire. They reported whether they had been exposed to stressful life events, vaccinations or other environmental factors. Patients were asked to rate the distress resulting from exposure to life events on a numerical rating scale (NRS: 0-10). Primary outcome variable was the variation of Bath Ankylosing Spondylitis Disease Activity Index (BASDAI) measured on two consecutive connections. Months where an event occurred were compared to months without events. The cutoff value of 1 is defined as the minimal clinically important variation for the BASDAI.

Results: The 272 enrolled SpA patients returned 3,388 questionnaires. Months where an abrupt and unexpected traumatic event occurred were associated with a significant increase of BASDAI of 0.57 [95\% CI: 0.29; 0.85] ( $\mathrm{p}<0.001)$. The higher the rating of distress, the larger the impact on BASDAI, reaching a clinically meaningful increase of $0.99[0.17 ; 1.82]$ for a VNS $\geq 9$. The effect of stressful events on BASDAI persisted during a median of 3 months. No other environmental factor was significantly associated with BASDAI variations.

Conclusion: Among stressful life events, abrupt and unexpected events were associated with transient worsening of disease activity in $\mathrm{SpA}$, which reached a clinically meaningful increase for the highest rating of distress. Association between vaccines and disease flare was not confirmed.

\section{Keywords:}

Spondyloarthritis, Epidemiology, Disease activity, Life change events 


\section{Introduction}

Spondyloarthritis $(\mathrm{SpA})$ is one of the most common inflammatory rheumatic diseases, affecting $0.40-1 \%$ of the adult Caucasian population [1]. The most characteristic symptoms of $\mathrm{SpA}$ are chronic pain and stiffness predominating in the axial skeleton, i.e. the spinal, pelvic and thoracic joints. Sustained inflammation can lead to structural damage such as erosions evolving into bony ankylosis of the sacro-iliac joints and the inter-vertebral disks and spinal ligaments. Peripheral arthritis, enthesitis and extra-articular inflammation, including anterior uveitis, psoriasis and inflammatory bowel disease (IBD) may also frequently occur in SpA. All these manifestations concur to functional impairment and a decrease in quality of life [2].

Albeit the exact cause of SpA remains largely unknown, heritability of this disorder is high [3]. The HLA-B27 allele is the most important genetic factor identified nearly 45 years ago and accounting for $30 \%$ to $50 \%$ of the overall genetic risk [3]. Several other genetic polymorphisms associated with SpA predisposition have recently been identified through large-scale genome-wide association studies [4]. However, a major part of SpA heritability still remains to be explained, as for other complex disorders.

On the other hand, the relative contribution of environmental factors to disease triggering and/or progression remains poorly characterized [2]. The disease course is typically characterized by a succession of flares and partial remissions that can readily be monitored by using self-administered validated questionnaires, such as the Bath Ankylosing Spondylitis Disease Activity Index (BASDAI) [5]. We previously conducted a prospective cohort study to investigate the putative impact of environmental factors on the triggering of SpA flares [6]. In this previous study, patients were asked to complete a standardized self-questionnaire, every three months, designed to evaluate disease activity, and to identify if they had been exposed since the previous connection to one of a predefined list of environmental factors suspected of being nonspecific stimulants of inflammatory response. Results showed that stressful life events, and to a lesser extent vaccines, may indeed influence the course of SpA [6]. However, this study had some limitations, such as a relatively long interval (i.e. 3 months) between two connections that exposed to memory biases. Moreover, no details were obtained regarding the type of stressful life event or the type of vaccine to which the patients were exposed. Also, the magnitude of variation of the different measures was rather mild at the population level, frequently below the minimal clinically important variations.

In order to investigate more thoroughly the relationships between $\mathrm{SpA}$ disease activity and environmental exposures, a new cohort was prospectively followed. The purpose of this new study was to expand and refine the previous results by using a shorter period between each questionnaire and by obtaining a detailed description of incoming stressful life events and vaccinations. 


\section{Methods}

\section{$\underline{\text { Patients' recruitment }}$}

The study population consisted of a dedicated cohort of adult (age $\geq 18 \mathrm{yrs}$ ) SpA patients fulfilling internationally validated classification criteria $[7,8]$. They were recruited on a voluntary basis through the Rheumatology Department of Ambroise Paré Hospital

(Boulogne Billancourt, France) or through the "Association Française des Spondylarthritiques", a self-help organisation for SpA patients. The study was approved by the Institutional Review Board of Ambroise Paré Hospital and informed consent was obtained from each participant. The SpA diagnosis was ascertained by qualified investigators (RSN or $\mathrm{MB}$ ) based on the following informations collected before inclusion: personal history of inflammatory back pain, buttock pain, peripheral arthritis, enthesitis, dactylitis, efficacy of non-steroidal anti-inflammatory drugs, uveitis, psoriasis, IBD, family history of SpA, advanced radiographic sacroiliitis (according to the modified New York criteria), evidence of sacro-iliitis on magnetic resonance imaging and HLA-B27 status. Consent to participate, having a confirmed diagnosis of $\mathrm{SpA}$ and regular access to an Internet connection were all required for inclusion in the study. Only patients fulfilling ASAS and/or Amor classification criteria for $\mathrm{SpA}$ were included in the analysis $[7,8]$. Part of the study population corresponded to a carryover of a first cohort, which was followed from December 2005 through October 2008 [6]. Participants who entered the present study were not informed of the results of the previous one, in order to minimize the risk of influencing their responses.

\section{$\underline{\text { Study conduct }}$}

This longitudinal observational study was carried during two years from May 2010 through April 2012. Patients were asked to log on every month to a secured website developed by the UMR-S 1136, as previously described [6], and to complete a standardized auto-questionnaire. Patients were enrolled from May 2010 through June 2011 and followedup until the end of the study period.

The following data were collected at the time of the first connection: demographic (age, gender, disease duration, history of present illness), socio-economical information, SpA disease history (independently assessed for validation of diagnosis), current cigarette-smoking habits (including Fagerstrom score [9], alcohol consumption and addiction (French version of CAGE score [10]), disease activity and severity by self-assessment measures (French versions of the BASDAI and Bath Ankylosing Spondylitis Functional Index (BASFI)) [11,12], and the Hospital Anxiety and Depression Scale (HADS) [13]. The cutoff values of 1 for BASDAI and 0.7 for BASFI are defined as the minimal clinically important variations for these variables.

At the next connections they reported whether they had been exposed since the previous connection to one of a predefined list of environmental factors suspected of being 
nonspecific stimulants of inflammatory response, and completed the BASDAI, and BASFI. In all cases it was specified that assessment of disease parameters should reflect symptoms over the week preceding each connection.

To test if disease activity was different between patients dropping out before study completion and those who carried on, we compared the mean trimestral BASDAI score during the last three months of participation of the formers to the BASDAI score of the same trimester of the latters. Such comparison was repeated every 3 months.

\section{Environmental factors studied}

At each follow-up connection, patients were asked to report their exposure since the previous connection (i.e. in the last month) to any of the following environmental factors that had previously been reported in the literature as possibly being associated with the triggering or disease activity of SpA or other inflammatory/autoimmune diseases [6,14-22].

Vaccinations: all the vaccinations recommended for adults by the French health authorities were listed in the questionnaire. Patients were asked to identify if they had received one or several of them.

Stressful life events: patients were asked to report the occurrence of life events that were felt to be stressful, difficult or traumatic. The proposed stressful events were derived from the Paykel list [23]. Abrupt and unexpected stressful life events were clearly identified (natural disasters, assault or sudden death of a loved one for example). In case of positive reply, patients were asked to complete a numerical rating scale (NRS), rating from 0 (least) to 10 (worst) the distress weight of the occurring life event.

Dust exposure: patients were asked if they had been exposed to a very dusty atmosphere, for example, via construction work or removal of dust (yes or no answer).

Solvent exposure: patients were asked if they had used any solvents, either in an occupational setting or while carrying out any 'do-it-yourself' activity (yes or no answer).

Surgical intervention: patients were asked if they had had a surgical operation (yes or no answer).

\section{Missing data}

Last observation carried forward (LOCF) was applied for patients who did not connect to the study site between 45 and 59 days since the last connection. The procedure was repeated if no connection had occurred between 60 and 90 days. When a patient did not connect to the study site for more than 90 days, his subsequent connections were deleted from the analysis. With this procedure, $10.6 \%$ of observations were added and $12.6 \%$ were deleted. 


\section{$\underline{\text { Statistical analyses }}$}

The aim of the statistical analysis was to estimate changes in BASDAI measures according to the occurrence of environmental factors. The primary outcome variable was the change in a given measure over a one-month period, computed as the difference of this measure at the end minus this measure at the start of the period ( $\triangle \mathrm{BASDAI})$. Working with the change in measure as a variable, rather than with the absolute level of it, allowed controlling for patients' characteristics that may affect its absolute level. The effect of exposure to a given environmental factor, vaccination for instance, was tested by comparing change in outcome measure over one month period where vaccination had occurred (i.e. "exposed periods") to change over periods where vaccination was not reported (i.e. "nonexposed periods").

For each patient and each type of event, we searched for all the sequences of two consecutive "non-exposed" and one "exposed" months (Figure 1). The $\triangle$ BASDAI of each of these consecutive months were calculated, and their means were compared with the paired Student t-test. Similar analyses were conducted for BASFI.

As multiple comparisons were performed, the Bonferroni correction was applied for endpoint analyses and the corrected p-value for statistical significance was set at 0.003 .

The persistence of an influence of incoming events on BASDAI was determined by Kaplan-Meier analysis. For this, we defined persistence as the period of time during which the BASDAI remained above the value reported just before the stressful event. Patients who remained above were censored at the time of the last report.

We also compared the average $\triangle \mathrm{BASDAI}$ between patients with an HADS anxiety score beneath 8 and those with a score at 8 and above, and between patients with an HADS depression score beneath 8 and those with a score at 8 and above (student t-test).

All statistical analyses were conducted using R 2.15. package.

\section{Role of the funding source}

The funders had no role in the design and conduct of the study; analysis, and interpretation of the data and preparation or approval of the manuscript. 


\section{Results}

Three hundred and seven patients having a diagnosis of SpA were recruited for enrollment in this study. Among them 27 could not be reached for classification criteria ascertainment, 4 never accessed to the website, 4 accessed only once for the baseline assessment and 272 patients answered at least to one monthly follow-up questionnaire. Finally, the analyses were conducted on 3,388 patient-connections made by 272 patients during the study period, of which 166 had participated to our previous study [6] and 106 were new participants.

The average duration of participation was 505 days (+/-159). The mean duration between two connections was 38.9 days $(+/-18.5)$. Each patient answered to an average of $13.0(+/-6.0)$ monthly questionnaires.

The baseline characteristics of the patients are shown in Table 1. Patients already included in the former study were older, had a longer disease duration and had a lower BASDAI at inclusion than those newly included [6]. On the HADS scoring, the mean level of anxiety was rather high (9.1), while the depression level was in the normal range of less than 8 (6.5). A majority of participants reported drinking alcohol (72.8\%), but only 17 patients had a possible addiction. Smokers represented $22.8 \%$ of the participants. More than half of the patients $(57 \%)$ had a professional activity at the time of inclusion.

The average trimestral BASDAI score did not vary significantly according to the duration of participation $(\mathrm{p}=0.42$; Appendix $\mathrm{A}$, table $\mathrm{S} 1$; See the supplementary material associated with this article online].

The impact of the occurrence of the studied events on BASDAI is shown in Table 2. Months where an abrupt and unexpected stressful life event had occurred were associated with a mean increase of BASDAI of 0.57 [95\% Confidence Interval (CI): 0.29; 0.85], compared to months without such occurrence $(\mathrm{p}<0.001)$. This increase was not different between patients with an HADS anxiety score beneath 8 and those with a score at 8 and above ( $\mathrm{p}=0.82$ ), nor between patients with an HADS depression score beneath 8 and those at 8 and above ( $\mathrm{p}=0.15$ ). Only the events with the higher rating of distress (i.e.VNS $\geq 9$ ) reached a clinically meaningful increase (mean $\triangle$ BASDAI: 0.99 [0.17; 1.82]). The effect of abrupt and unexpected stressful life event on BASDAI persisted for a median of 3 months (95\% CI 2-4) and $25 \%$ of the patients remained affected more than 8 months (95\% CI: 4-18) (Figure 2).

Among other environmental factors, two showed nominal p-value for statistical association with increased BASDAI, although not significant after Bonferroni correction: dust heavy exposure (mean $\triangle \mathrm{BASDAI}:+0.33$ [0.01; 0.64], $\mathrm{p}=0.04$ ) and seasonal influenza vaccination (mean $\triangle$ BASDAI: 0.40 [0.02; 0.78], p=0.04) (Table 2). 
Similarly as for BASDAI, the months where an abrupt and unexpected stressful life event had occurred were associated with a mean increase of BASFI of 0.27 [95\% CI: 0.13; 0.41], compared to months without such occurrence $(\mathrm{p}<0.001)$ (Table 3). This increase was close to the minimal clinically important cutoff value only for events with a VNS $\geq 9$ (mean $\triangle$ BASFI: 0.66 [95\% CI: 0.26; 1.06]). A significant increase of BASFI was also observed after dust heavy exposure $(0.26[0.10 ; 0.42], \mathrm{p}=0.001)$. No other event occurrence was associated with a BASFI modification.

\section{Discussion}

This prospective study confirms that stressful events are followed by a slight increase of SpA disease activity, as assessed by BASDAI variation. Only stressful life events that are abrupt and unexpected and that are rated as highly distressing reach a clinically meaningful increase. No other environmental factor studied here has a significant impact on disease activity, including vaccines. Noteworthy however, dust heavy exposure was associated to a significant (but non clinically meaningful) worsening of SpA functional score but not of disease activity.

This study showed that abrupt and unexpected life events only, not ongoing stressors, were associated to BASDAI and BASFI worsening. Putting a date on the beginning of a life event may be challenging in the case of ongoing stressors, such as marital or work-related problems for example. On the contrary, abrupt stressors occurring outside of a person's control, such as natural disasters or assault for example, are easier to date, especially in a prospective study, making them more identifiable to patients. There is a widespread belief that acute psychological stress may lead to disease. Indeed, it has been shown that stress contributes to a variety of disease processes and has measurable impacts on the hypothalamicpituitary-adrenocortical axis, the sympathetic-adrenal-medullary system and the natural and specific immunity [24-26]. The suspicion that stress and traumatic life events are associated with the course or triggering of $\mathrm{SpA}$, was already reported in some retrospective, crosssectional or case reports studies [27-31]. Even if it is not yet possible to readily establish straightforward relationship between psychological stress and the human immune system, available evidences suggest that acute and chronic stressors determine different kind of changes in the immune response [32]. There is a large body of evidence demonstrating that stress elevates inflammation and that some stressors may be more important than others [3337]. This biological plausibility of a differential effect of stressors according to their characteristics, together with the clear temporal relationship and the dose-effect pattern observed in the present study, are arguments that favor a causal relationship between stressful life events and disease activity of SpA. Exploring the relationship between psychological 
symptoms and inflammation is important because it could help to design interventions aiming at reducing stress and the risk of SpA flare, consequently.

Even if the magnitude of variation of the BASDAI following stressful events was rather mild at the population level, variations could be more important at the patient level, and clinically meaningful in some cases. Indeed, the mean variation of 0.99 for the BASDAI following highly distressing abrupt and unexpected events, almost reaches the cut-off value of 1 defined as the minimal clinically important variation for this variable [38].

Beside abrupt and unexpected stressors, dust heavy exposure was associated with worsening of the functional index (BASFI) but not of the disease activity index (BASDAI). One possible interpretation of this observation is that dust heavy exposure was associated with physically demanding occupations that resulted in functional worsening but had no effect on disease activity.

Concerns about adverse effects of vaccines are associated with low vaccine coverage rates [39]. The results presented here may help reassure patients with spondyloarthritis that vaccines do not increase disease activity.

The principal strengths of this study were its prospective design, the use of a standardized questionnaire applied to a dedicated SpA cohort and the monthly basis of questionnaire administration that limited memory biases. Moreover, each patient served as its own control, limiting the risk of information biases due to a lack of control population.

This study had some limitation, however. Notably, we measured the impact of environmental factors on the perceived severity of symptoms, but not on objective marker of inflammation. Thus, we could not demonstrate that what we measured truly corresponded to an increase in disease activity, even though the BASDAI is an accepted proxy for this purpose. BASDAI score could partly be explained by psychological distress [40]. For instance, it has been shown in the context of rheumatoid arthritis that depressive symptoms could influence patient-reported symptoms, but had no impact on swollen joints and acute-phase reactants [41]. On the other hand, our results were not affected by the level of depression or anxiety, which militates against such interpretation applying to our study.

To conclude, this study confirms with enhanced methodology our previous demonstration that stressful events, but not vaccines could be followed by a worsening of SpA activity [6]. It also showed that such impact was only significant and clinically meaningful for abrupt stressors with the highest rating of distress and that it could last several months. These conclusions bear strong implication for the care of SpA and for understanding factors that influence the evolution of this chronic disorder. 


\section{Acknowledgments:}

This work was supported by the National Hospital Clinical Research Program [PHRC, AOM02020] and an unrestricted grant from UCB Pharma.

This work was previously presented at the American College of Rheumatology Annual Scientific Meeting, San Diego, October 2013 (Luo GG, Boelle PY, Turbelin C, Said Nahal R, Zeboulon N, D'Agostino MA, Kerneis S, Hanslik T, Breban M. Impact of stressful life events on disease activity in spondyloarthritis: results of the CoEnv2 prospective cohort study).

\section{Disclosure of interest with regard to the work:}

- SK declares having received travel grants from Pfizer Vaccines.

- TH declares having received travel grants from Sanofi Pasteur MSD.

\section{Appendix A. Supplementary data}

Supplementary data (table S1) associated with this article can be found in the online version at ... 


\section{References}

1- Costantino F, Talpin A, Said-Nahal R, Goldberg M, Henny J, Chiocchia G, Garchon HJ, Zins M, Breban M. Prevalence of spondyloarthritis in reference to HLA-B27 in the French population: results of the GAZEL cohort. Ann Rheum Dis. 2015 ;74(4):689-93.

2- $\quad$ Braun J, Sieper J. Ankylosing spondylitis. Lancet. 2007;369(9570):1379-90.

3- $\quad$ Breban M, Miceli-Richard C, Zinovieva E, Monnet D, Said-Nahal R. The genetics of spondyloarthropathies. Joint Bone Spine 2006;73(4):355-62.

4- International Genetics of Ankylosing Spondylitis Consortium (IGAS), Cortes A, Hadler J, Pointon JP, Robinson PC, Karaderi T, et al. Identification of multiple risk variants for ankylosing spondylitis through high-density genotyping of immune-related loci. Nat Genet 2013;45:730-8.

5- Garrett S, Jenkinson T, Kennedy LG, Whitelock H, Gaisford P, Calin A. A new approach to defining disease status in ankylosing spondylitis: the Bath Ankylosing Spondylitis Disease Activity Index. J Rheumatol. 1994;21(12):2286-91.

6- Zeboulon-Ktorza N, Boelle PY, Nahal RS, D'agostino MA, Vibert JF, Turbelin C, et al. Influence of environmental factors on disease activity in spondyloarthritis: a prospective cohort study. J. Rheumatol. 2013;40(4):469-75.

7- $\quad$ Rudwaleit M, van der Heijde D, Landewé R, Listing J, Akkoc N, Brandt J, Braun J, Chou CT, Collantes-Estevez E, Dougados M, Huang F, Gu J, Khan MA, Kirazli Y, Maksymowych WP, Mielants H, Sørensen IJ, Ozgocmen S, Roussou E, Valle-Oñate R, Weber U, Wei J, Sieper J. The development of Assessment of SpondyloArthritis international Society classification criteria for axial spondyloarthritis (part II): validation and final selection. Ann Rheum Dis. 2009;68(6):777-83.

8- $\quad$ Amor B, Dougados M, Mijiyawa M. [Criteria of the classification of spondylarthropathies]. Rev. Rhum. Mal. Ostéo-Articul. 1990;57(2):85-9.

9- $\quad$ Fagerström KO. Measuring degree of physical dependence to tobacco smoking with reference to individualization of treatment. Addict. Behav. 1978;3(3-4):235-41.

10- Kitchens JM. Does this patient have an alcohol problem? JAMA J. Am. Med. Assoc. 1994;272(22):1782-7.

11- Claudepierre P, Sibilia J, Goupille P, Flipo RM, Wendling D, Eulry F, Clerc D, Berthelot JM, Vergne P, Roudot-Thoraval F, Larget-Piet B, Chevalier X Evaluation of a French version of the Bath Ankylosing Spondylitis Disease Activity Index in patients with spondyloarthropathy. J Rheumatol. 1997;24(10):1954-8.

12- Calin A, Garrett S, Whitelock H, Kennedy LG, O'Hea J, Mallorie P, Jenkinson T. A new approach to defining functional ability in ankylosing spondylitis: the development of the Bath Ankylosing Spondylitis Functional Index. J Rheumatol. 1994

Dec;21(12):2281-5.

13- $\quad$ Lepine JP, Godchau M, Brun P. Anxiety and depression in inpatients. Lancet. 1985;2(8469-70):1425-6.

14- De Brouwer SJM, Kraaimaat FW, Sweep FCGJ, Creemers MCW, Radstake TRDJ, van Laarhoven AIM, et al. Experimental stress in inflammatory rheumatic diseases: a review of psychophysiological stress responses. Arthritis Res. Ther. 2010;12(3):R89.

15- Karaiskos D, Mavragani CP, Makaroni S, Zinzaras E, Voulgarelis M, Rabavilas A, et al. Stress, coping strategies and social support in patients with primary Sjögren's syndrome prior to disease onset: a retrospective case-control study. Ann. Rheum. Dis. 2009;68(1):40-6.

16- Kemeny ME, Schedlowski M. Understanding the interaction between psychosocial stress and immune-related diseases: a stepwise progression. Brain. Behav. Immun. 2007;21(8):1009-18.

17- Lane SE, Watts RA, Bentham G, Innes NJ, Scott DGI. Are environmental factors important in primary systemic vasculitis? A case-control study. Arthritis Rheum. 2003;48(3):814-23.

18- Mohr DC, Hart SL, Julian L, Cox D, Pelletier D. Association between stressful life events and exacerbation in multiple sclerosis: a meta-analysis. BMJ.

2004;328(7442):731. 
19- Parks CG, Walitt BT, Pettinger M, Chen J-C, de Roos AJ, Hunt J, et al. Insecticide use and risk of rheumatoid arthritis and systemic lupus erythematosus in the Women's Health Initiative Observational Study. Arthritis Care Res. 2011;63(2):184-94.

20- Pattison E, Harrison BJ, Griffiths CEM, Silman AJ, Bruce IN. Environmental risk factors for the development of psoriatic arthritis: results from a case-control study. Ann. Rheum. Dis. 2008;67(5):672-6.

21- Reiche EMV, Nunes SOV, Morimoto HK. Stress, depression, the immune system, and cancer. Lancet Oncol. 2004;5(10):617-25.

22- Stolt P, Yahya A, Bengtsson C, Källberg H, Rönnelid J, Lundberg I, et al. Silica exposure among male current smokers is associated with a high risk of developing ACPA-positive rheumatoid arthritis. Ann. Rheum. Dis. 2010;69(6):1072-6.

23- $\quad$ Paykel ES. The Interview for Recent Life Events. Psychol. Med. 1997;27(2):301-10.

24- Segerstrom SC, Miller GE. Psychological stress and the human immune system: a meta-analytic study of 30 years of inquiry. Psychol. Bull. 2004;130(4):601-30.

25- Eitel I, von Knobelsdorff-Brenkenhoff F, Bernhardt P, Carbone I, Muellerleile K, Aldrovandi A, Francone M, Desch S, Gutberlet M, Strohm O, Schuler G, SchulzMenger J, Thiele H, Friedrich MG. Clinical characteristics and cardiovascular magnetic resonance findings in stress (takotsubo) cardiomyopathy. JAMA. $2011 \mathrm{Jul}$ 20;306(3):277-86.

26- Pongratz G, Straub RH. Role of peripheral nerve fibres in acute and chronic inflammation in arthritis. Nat Rev Rheumatol. 2013;9(2):117-26.

27- Claudepierre P, Sibilia J, Roudot-Thoraval F, Flipo RM, Wendling D, Goupille P, et al. Factors linked to disease activity in a French cohort of patients with spondyloarthropathy. J. Rheumatol. 1998;25(10):1927-31.

28- Averns HL, Oxtoby J, Taylor HG, Jones PW, Dziedzic K, Dawes PT. Smoking and outcome in ankylosing spondylitis. Scand. J. Rheumatol. 1996;25(3):138-42.

29- Costenbader K, Laden F. What do pesticides, farming, and dose effects have to do with the risk of developing connective tissue disease? Arthritis Care Res. 2011;63(2):175-7.

30- Olivieri I, Gherardi S, Bini C, Trippi D, Ciompi ML, Pasero G. Trauma and seronegative spondyloarthropathy: rapid joint destruction in peripheral arthritis triggered by physical injury. Ann. Rheum. Dis. 1988;47(1):73-6.

31- Zochling J, Bohl-Bühler MHJ, Baraliakos X, Feldtkeller E, Braun J. Infection and work stress are potential triggers of ankylosing spondylitis. Clin. Rheumatol. 2006;25(5):660-6.

32- Pongratz G, Straub RH. The sympathetic nervous response in inflammation. Arthritis Res Ther. 2014;16(6):504.

33- Lee YC, Agnew-Blais J, Malspeis S, Keyes K, Costenbader K, Kubzansky LD, Roberts AL, Koenen KC, Karlson EW. Post-traumatic stress disorder and risk for incident rheumatoid arthritis. Arthritis Care Res 2016;68(3):292-8.

34- Evers AW, Verhoeven EW, van Middendorp H, Sweep FC, Kraaimaat FW, Donders AR, Eijsbouts AE, van Laarhoven AI, de Brouwer SJ, Wirken L, Radstake TR, van Riel PL. Does stress affect the joints? Daily stressors, stress vulnerability, immune and HPA axis activity, and short-term disease and symptom fluctuations in rheumatoid arthritis. Ann Rheum Dis. 2014;73(9):1683-8.

35- Thorarensen SM, Lu N, Ogdie A, Gelfand JM, Choi HK, Love TJ. Physical trauma recorded in primary care is associated with the onset of psoriatic arthritis among patients with psoriasis. Ann Rheum Dis. 2017;76(3):521-525.

36- Cohen S, Janicki-Deverts D, Miller GE. Psychological stress and disease. JAMA J. Am. Med. Assoc. 2007;298(14):1685-7.

37- Cohen S, Janicki-Deverts D, Doyle WJ, Miller GE, Frank E, Rabin BS, Turner RB. Chronic stress, glucocorticoid receptor resistance, inflammation, and disease risk. Proc Natl Acad Sci U S A. 2012 Apr 17;109(16):5995-9.

38- Pavy S, Brophy S, Calin A. Establishment of the minimum clinically important difference for the bath ankylosing spondylitis indices: a prospective study. J. Rheumatol. 2005;32(1):80-5. 
39- Fabre S, Molto A, Kreis S, Hudry C, Fautrel B, Pertuiset E, et al. Is the widely-used score in axial spondyloarthritis, Bath Ankylosing Spondylitis Disease Activity Index, influenced by patients' optimism? A cross-sectional study of 206 patients. Joint Bone Spine. 2017;84(5):629-630

40- Brocq O, Acquacalda E, Berthier F, Albert C, Bolla G, Millasseau E, et al. Influenza and pneumococcal vaccine coverage in 584 patients taking biological therapy for chronic inflammatory joint: A retrospective study. Joint Bone Spine. 2016;83(2):155-9.

41- Rathbun AM, Harrold LR, Reed GW. Temporal effect of depressive symptoms on the longitudinal evolution of rheumatoid arthritis disease activity. Arthritis Care Res 2015;67(6):765-75. 


\section{Figures}

Figure 1. Study design for calculating changes in BASDAI ( $\triangle \mathrm{BASDAI}$ ) in months during which an exposition to an environmental factor occurred, as compared to months during which no exposition to an environmental factor occurred.

Figure 2. Persistence of the influence of acute and unexpected stressful life on BASDAI (proportion of patients).

The Kaplan-Meier graph shows evolution of the proportion of patients with increased BASDAI over time (months), following occurrence of an acute and unexpected stressful life event 


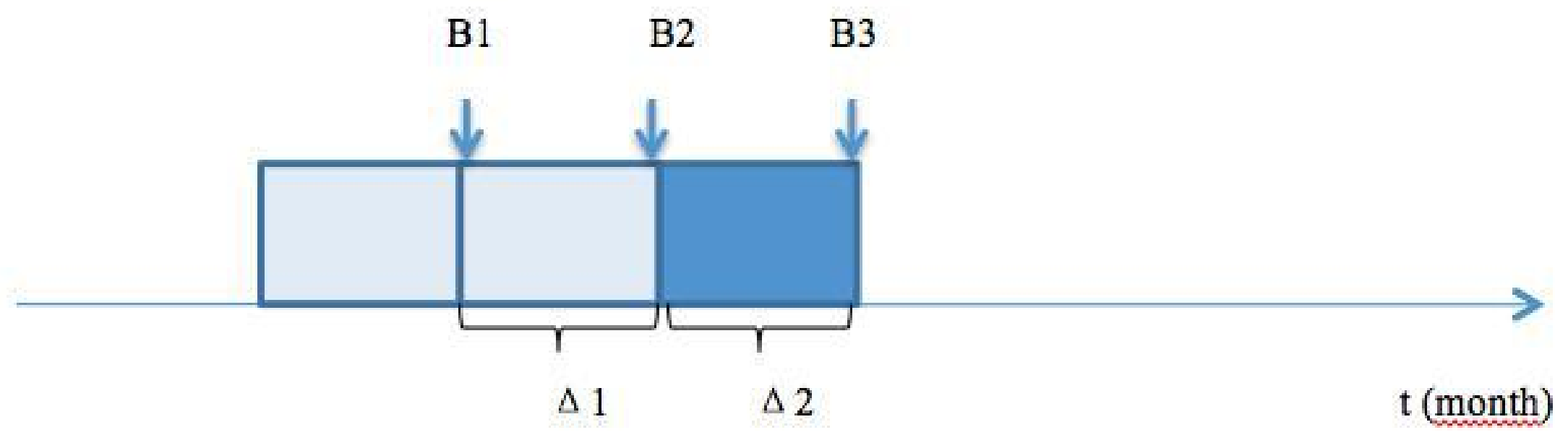

Period with event

Period without event

$\triangle$ BASDA $1=\mathrm{B} 2-\mathrm{B} 1$

$\triangle$ BASDAI $2=\mathrm{B} 3-\mathrm{B} 2$ 


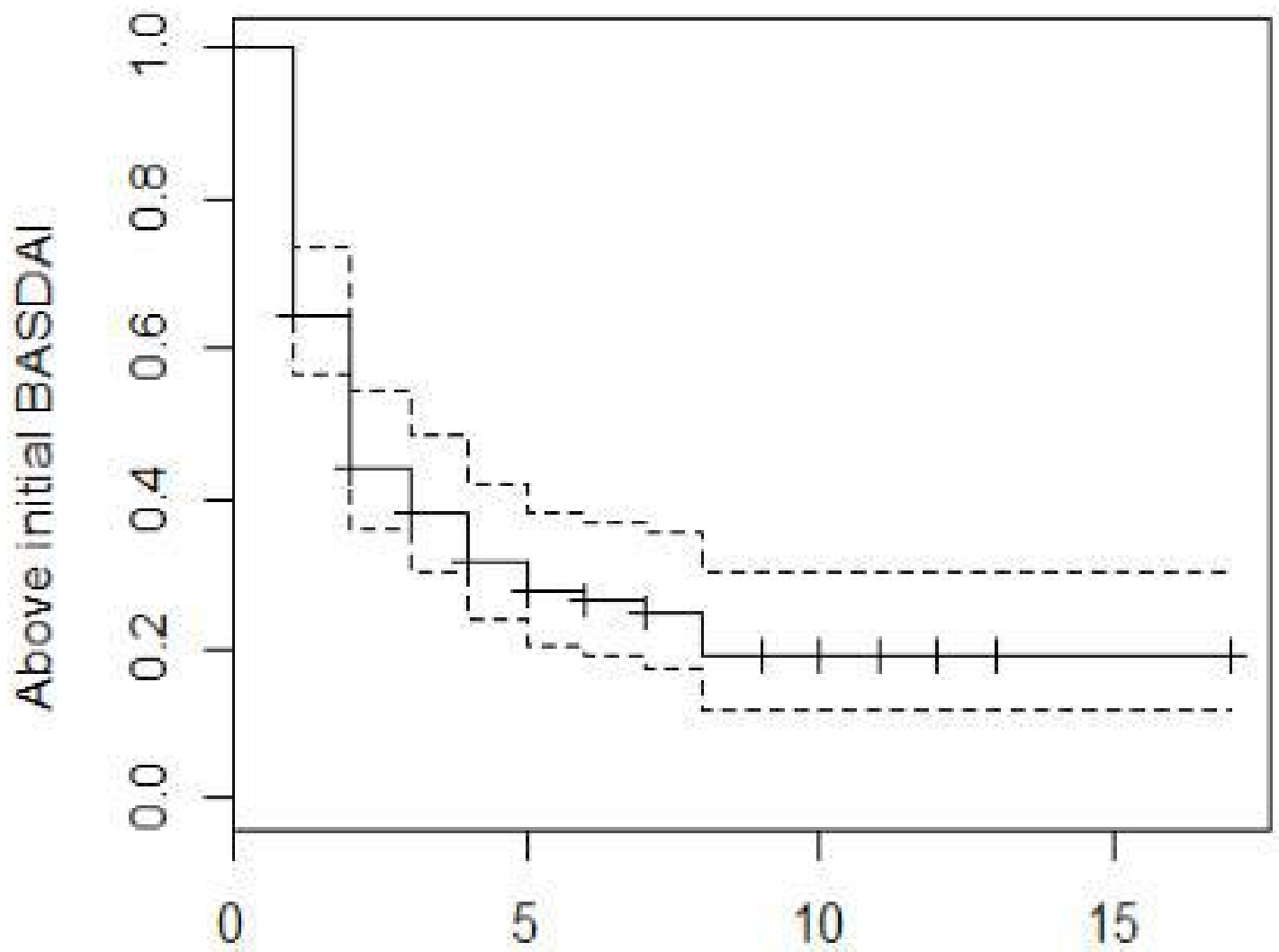

Time after abrupt and unexpected life event (months) 
Table 1. Characteristics of patients at inclusion according to their participation to a previous cohort [6]

\begin{tabular}{|c|c|c|c|c|}
\hline Characteristics & $\begin{array}{c}\text { All } \\
(\mathrm{n}=\mathbf{2 7 2})\end{array}$ & $\begin{array}{c}\text { Carryover } \\
\text { population } \\
(\mathbf{n}=166)\end{array}$ & $\begin{array}{c}\text { Entering } \\
\text { population } \\
(\mathbf{n}=106)\end{array}$ & $\mathbf{P}$ \\
\hline Age at inclusion in years, mean \pm SD & $48.0 \pm 11.8$ & $49.1 \pm 11.1$ & $46.2 \pm 12.7$ & 0.05 \\
\hline Male percentage, $(\%)$ & 38.6 & 38.6 & 38.7 & $\mathrm{~ns}$ \\
\hline $\mathrm{BMI}$, mean $\pm \mathrm{SD}$ & $25.3 \pm 5.1$ & $25.5 \pm 5.3$ & $25.0 \pm 4.6$ & ns \\
\hline Age at onset in years, mean $\pm \mathrm{SD}$ & $25.6 \pm 9.8$ & $24.7 \pm 9.9$ & $26.9 \pm 9.6$ & $\mathrm{~ns}$ \\
\hline Disease duration in years, mean $\pm \mathrm{SD}$ & $22.4 \pm 12.6$ & $24.3 \pm 11.7$ & $19.4 \pm 13.4$ & 0.002 \\
\hline$H L A-B 27$ positivity, $\%$ & 78.5 & 81.7 & 73.3 & ns \\
\hline \multicolumn{5}{|l|}{ Axial manifestations } \\
\hline - $\quad$ Inflammatory back pain, $\%$ & 95.6 & 95.2 & 96.2 & $\mathrm{~ns}$ \\
\hline - $\quad$ Radiographic sacroiliitis, \%* & 44.6 & 47.1 & 40.6 & $\mathrm{~ns}$ \\
\hline \multicolumn{5}{|l|}{ Peripheral manifestations } \\
\hline - $\quad$ Peripheral arthritis, $\%$ & 34.3 & 35.8 & 32.1 & ns \\
\hline - $\quad$ Dactylitis, $\%$ & 18.1 & 20.0 & 15.2 & ns \\
\hline - $\quad$ Heel pain, $\%$ & 51.1 & 51.5 & 50.5 & ns \\
\hline \multicolumn{5}{|l|}{ Extra-articular manifestations } \\
\hline - $\quad$ Uveitis, \% & 25.3 & 28.0 & 21.0 & ns \\
\hline - $\quad$ Psoriasis, $\%$ & 28.3 & 29.1 & 26.9 & $\mathrm{~ns}$ \\
\hline - Inflammatory bowel disease, $\%$ & 7.4 & 6.1 & 9.5 & $\mathrm{~ns}$ \\
\hline \multicolumn{5}{|l|}{ Classification criteria fulfillment } \\
\hline - $\quad$ New York, $\%$ & 44.6 & 47.1 & 40.6 & $\mathrm{~ns}$ \\
\hline - $\quad$ Amor, $\%$ & 98.9 & 99.4 & 98.0 & $\mathrm{~ns}$ \\
\hline - $\quad$ ASAS Axial SpA, $\%$ & 83.6 & 86.1 & 79.8 & $\mathrm{~ns}$ \\
\hline - $\quad$ ASAS Peripheral SpA, $\%$ & 10.9 & 10.4 & 11.9 & $\mathrm{~ns}$ \\
\hline BASDAI $(0-10)$, mean \pm SD & $4.23 \pm 2.04$ & $3.98 \pm 1.97$ & $4.62 \pm 2.10$ & 0.01 \\
\hline BASFI $(0-100)$, mean \pm SD & $33.9 \pm 24.5$ & $32.8 \pm 23.9$ & $35.7 \pm 25.4$ & $\mathrm{~ns}$ \\
\hline \multicolumn{5}{|l|}{ Treatment } \\
\hline - $\quad$ NSAIDs, $\%$ & 43.8 & $39.8^{-}$ & $50 . \overline{0}$ & $\mathrm{~ns}$ \\
\hline - $\quad$ Corticosteroids, $\%$ & 5.9 & 7.2 & 3.8 & $\mathrm{~ns}$ \\
\hline - $\quad$ DMARDs, $\%$ & 17.3 & 15.1 & 20.8 & $\mathrm{~ns}$ \\
\hline - $\quad$ Biologics, $\%$ & 40.4 & 41.6 & 38.7 & $\mathrm{~ns}$ \\
\hline HADS anxiety $(0-21)$, mean \pm SD & $9.1 \pm 4.1$ & $8.8 \pm 4.1$ & $9.6 \pm 4.2$ & $\mathrm{~ns}$ \\
\hline HADS depression $(0-21)$, mean \pm SD & $6.5 \pm 3.9$ & $6.3 \pm 4.1$ & $6.8 \pm 3.5$ & $\mathrm{~ns}$ \\
\hline Current smokers, $\%$ & 22.8 & 21.1 & 25.5 & $\mathrm{~ns}$ \\
\hline - $\quad$ Fagerström score $(0-10)$, mean $\pm \mathrm{SD}$ & $2.4 \pm 2.5$ & $2.4 \pm 2.6$ & $2.4 \pm 2.6$ & $\mathrm{~ns}$ \\
\hline Alcohol consumption (occasional or regular), $\%$ & 72.8 & 72.9 & 72.6 & $\mathrm{~ns}$ \\
\hline - $\quad$ CAGE score $(0-4)$, mean \pm SD & $0.3 \pm 0.8$ & $0.4 \pm 0.8$ & $0.3 \pm 0.7$ & $\mathrm{~ns}$ \\
\hline Employment, \% & 57.0 & 60.9 & 50.9 & ns \\
\hline
\end{tabular}

The registered manifestations correspond to those present at the time of examination, or retrieved from past-medical history.

SD: standard deviation; BMI: body mass index; ASAS: Assessment of SpondyloArthritis Society; BASDAI: Bath Ankylosing Spondylitis Disease Activity Index; BASFI: Bath Ankylosing Spondylitis Functional Index; NSAIDs: non steroidal antiinflammatory drugs; DMARDs: disease modifying anti rheumatic drugs; HADS: Hospital Anxiety and Depression scale; CAGE: Cut-down, Annoyed, Guilty, Eye-opener

* Refers to radiographic sacroiliitis $\geq$ grade II bilateral or grade III unilateral 
Table 2. Changes of BASDAI during periods with and without events.

\begin{tabular}{|c|c|c|c|c|c|c|}
\hline Types of exposure & $\begin{array}{l}\text { Number of events } \\
\text { during the study } \\
\text { periods }\end{array}$ & $\begin{array}{l}\text { Number of patients } \\
\text { in which the events } \\
\text { occurred }\end{array}$ & $\begin{array}{l}\text { Mean of } \triangle B A S D A I \\
\text { of period without } \\
\text { events (sd) }\end{array}$ & $\begin{array}{l}\text { Mean of } \triangle B A S D A I \\
\text { of period with } \\
\text { events (sd) }\end{array}$ & $\begin{array}{l}\text { Mean difference of } \\
\Delta B A S D A I \text { between } \\
\text { periods with and } \\
\text { without events } \\
{[95 \% \mathrm{CI}]}\end{array}$ & p-value* \\
\hline $\begin{array}{l}\text { Abrupt and unexpected } \\
\text { stressful life events }\end{array}$ & 169 & 107 & $-0.19(1.13)$ & $0.38(1.08)$ & $0.57[0.29 ; 0.85]$ & $<0.001$ \\
\hline Rating of distress $<5$ & 38 & 31 & $-0.12(1.09)$ & $0.07(1.11)$ & $0.19[-0.41 ; 0.79]$ & 0.52 \\
\hline Rating of distress $\geq 5$ & 131 & 87 & $-0.21(1.14)$ & $0.47(1.06)$ & $0.68[0.36 ; 1.00]$ & $<0.001$ \\
\hline Rating of distress $\geq 7$ & 76 & 58 & $-0.16(1.18)$ & $0.53(1.02)$ & $0.69[0.25 ; 1.13]$ & 0.003 \\
\hline Rating of distress $\geq 9$ & 22 & 21 & $-0.28(1.34)$ & $0.71(0.94)$ & $0.99[0.17 ; 1.82]$ & 0.020 \\
\hline Stressful life events & 219 & 96 & $0.07(1.33)$ & $0.04(1.29)$ & $-0.03[-0.32 ; 0.26]$ & 0.86 \\
\hline Financial problem & 125 & 78 & $0.12(1.27)$ & $0.04(1.14)$ & $-0.08[-0.43 ; 0.26]$ & 0.64 \\
\hline Work related problem & 56 & 35 & $-0.16(1.60)$ & $0.10(1.34)$ & $0.25[-0.38 ; 0.89]$ & 0.42 \\
\hline Couple problem & 153 & 84 & $-0.07(1.23)$ & $0.06(1.18)$ & $0.13[-0.20 ; 0.46]$ & 0.43 \\
\hline Bereavement & 116 & 82 & $-0.12(1.16)$ & $0.24(1.30)$ & $0.36[-0.03 ; 0.75]$ & 0.07 \\
\hline Problem with children & 123 & 76 & $0.05(1.40)$ & $-0.18(1.30)$ & $-0.24[-0.64 ; 0.17]$ & 0.26 \\
\hline Vaccinations (all vaccines) & 116 & 77 & $-0.12(1.14)$ & $0.19(1.22)$ & $0.32[-0.05 ; 0.68]$ & 0.09 \\
\hline Influenza & 104 & 66 & $-0.17(1.16)$ & $0.23(1.13)$ & $0.40[0.02 ; 0.78]$ & 0.04 \\
\hline Other & 24 & 23 & $0.08(0.95)$ & $-0.23(1.38)$ & $-0.31[-1.11 ; 0.49]$ & 0.43 \\
\hline Surgical intervention & 57 & 49 & $0.06(1.25)$ & $-0.05(1.52)$ & $-0.11[-0.80 ; 0.58]$ & 0.75 \\
\hline Dust heavy exposure & 149 & 96 & $0.00(1.14)$ & $0.33(1.20)$ & $0.33[0.01 ; 0.64]$ & 0.04 \\
\hline Exposure to agricultural dust & 68 & 43 & $-0.19(0.88)$ & $0.15(1.01)$ & $0.34[-0.03 ; 0.72]$ & 0.07 \\
\hline Solvent exposure & 138 & 82 & $0.15(1.13)$ & $0.04(1.12)$ & $-0.11[-0.40 ; 0.18]$ & 0.47 \\
\hline
\end{tabular}

* The corrected p-value for statistical significance was set at 0.003 . 
Table 3. Changes of BASFI during periods with and without events.

\begin{tabular}{|c|c|c|c|c|c|c|}
\hline Types of exposure & $\begin{array}{l}\text { Number of events } \\
\text { during the study } \\
\text { periods }\end{array}$ & $\begin{array}{l}\text { Number of patients } \\
\text { in which the events } \\
\text { occurred }\end{array}$ & $\begin{array}{l}\text { Mean of } \triangle B A S F I \\
\text { of period without } \\
\text { events (sd) }\end{array}$ & $\begin{array}{l}\text { Mean of } \triangle B A S F I \\
\text { of period with } \\
\text { events (sd) }\end{array}$ & $\begin{array}{l}\text { Mean difference of } \\
\Delta B \text { ASFI between } \\
\text { periods with and } \\
\text { without events } \\
{[95 \% \mathrm{CI}]}\end{array}$ & p-value* \\
\hline $\begin{array}{l}\text { Abrupt and unexpected } \\
\text { stressful life events }\end{array}$ & 169 & 107 & $3.85(2.56)$ & $4.12(2.61)$ & $0.27[0.13 ; 0.41]$ & $<0.001$ \\
\hline Rating of distress $<5$ & 38 & 31 & $2.71(1.85)$ & $2.87(1.81)$ & $0.16[-0.14 ; 0.46]$ & 0.29 \\
\hline Rating of distress $\geq 5$ & 131 & 87 & $4.19(2.65)$ & $4.48(2.70)$ & $0.30[0.14 ; 0.46]$ & $<0.001$ \\
\hline Rating of distress $\geq 7$ & 76 & 58 & $4.59(2.72)$ & $5.04(2.75)$ & $0.44[0.24 ; 0.65]$ & $<0.001$ \\
\hline Rating of distress $\geq 9$ & 22 & 21 & $4.90(3.28)$ & $5.55(3.22)$ & $0.66[0.26 ; 1.06]$ & 0.003 \\
\hline Stressful life events & 219 & 96 & $3.97(2.61)$ & $3.98(2.57)$ & $0.02[-0.11 ; 0.14]$ & 0.81 \\
\hline Financial problem & 125 & 78 & $3.85(2.70)$ & $3.79(2.56)$ & $-0.06[-0.23 ; 0.11]$ & 0.51 \\
\hline Work related problem & 56 & 35 & $3.39(2.48)$ & $3.31(2.37)$ & $-0.08[-0.39 ; 0.22]$ & 0.58 \\
\hline Couple problem & 153 & 84 & $3.13(2.35)$ & $3.21(2.34)$ & $0.08[-0.05 ; 0.20]$ & 0.24 \\
\hline Bereavement & 116 & 82 & $3.94(2.29)$ & $4.04(2.34)$ & $0.10[-0.07 ; 0.27]$ & 0.25 \\
\hline Problem with children & 123 & 76 & $4.16(2.64)$ & $4.12(2.73)$ & $-0.04[-0.19 ; 0.12]$ & 0.62 \\
\hline Vaccinations (all vaccines) & 116 & 77 & $4.47(2.62)$ & $4.49(2.59)$ & $0.02[-0.15 ; 0.19]$ & 0.85 \\
\hline Influenza & 104 & 66 & $4.65(2.67)$ & $4.70(2.58)$ & $0.05[-0.14 ; 0.23]$ & 0.62 \\
\hline Other & 24 & 23 & $3.25(2.34)$ & $2.93(2.34)$ & $-0.32[-0.69 ; 0.04]$ & 0.08 \\
\hline Surgical intervention & 57 & 49 & $4.24(2.67)$ & $4.53(2.80)$ & $0.29[-0.02 ; 0.61]$ & 0.07 \\
\hline Dust heavy exposure & 149 & 96 & $3.59(2.65)$ & $3.85(2.75)$ & $0.26[0.10 ; 0.42]$ & 0.001 \\
\hline Exposure to agricultural dust & 68 & 43 & $3.18(2.71)$ & $3.39(2.81)$ & $0.21[0.00 ; 0.42]$ & 0.05 \\
\hline Solvent exposure & 138 & 82 & $3.70(2.60)$ & $3.72(2.42)$ & $0.02[-0.16 ; 0.20]$ & 0.83 \\
\hline
\end{tabular}

* The corrected p-value for statistical significance was set at 0.003 . 